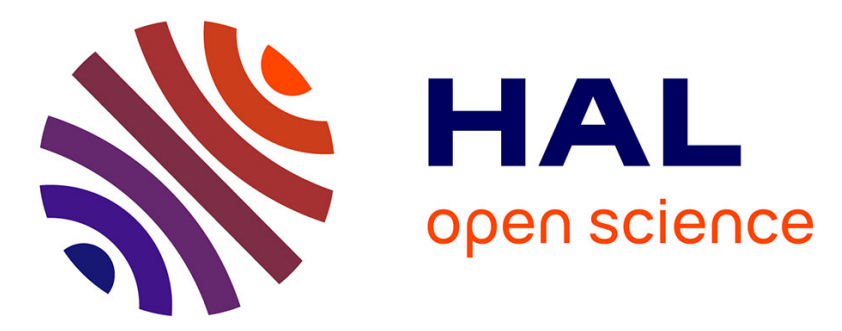

\title{
Modelling the voltammetry of adsorbed enzymes and molecular catalysts
}

Vincent Fourmond, Christophe Léger

\section{To cite this version:}

Vincent Fourmond, Christophe Léger. Modelling the voltammetry of adsorbed enzymes and molecular catalysts. Current Opinion in Electrochemistry, 2017, 1 (1), pp.110-120. 10.1016/j.coelec.2016.11.002 . hal-01440516

\section{HAL Id: hal-01440516 https://hal-amu.archives-ouvertes.fr/hal-01440516}

Submitted on 16 Apr 2018

HAL is a multi-disciplinary open access archive for the deposit and dissemination of scientific research documents, whether they are published or not. The documents may come from teaching and research institutions in France or abroad, or from public or private research centers.
L'archive ouverte pluridisciplinaire HAL, est destinée au dépôt et à la diffusion de documents scientifiques de niveau recherche, publiés ou non, émanant des établissements d'enseignement et de recherche français ou étrangers, des laboratoires publics ou privés. 


\title{
Modelling the voltammetry of adsorbed enzymes and molecular catalysts [pre-print] Current Opinion In Electrochemistry (2017) doi: $10.1016 /$ j.coelec.2016.11.002
}

\author{
Vincent Fourmond ${ }^{\star}$ and Christophe Léger ${ }^{\star}$ \\ Aix Marseille Univ., CNRS, Laboratoire de Bioénergétique et Ingénierie des Protéines, \\ UMR7281, Marseille,France.bip06.fr, @BIP6_Marseille, \\ fourmond@imm.cnrs.fr, leger@imm.cnrs.fr
}

\begin{abstract}
When redox enzymes are attached to electrodes and undergo direct electron transfer, their voltammetric responses exhibit diverse shapes that, if analyzed correctly, may inform about various aspects of the catalytic mechanism. Here we review the models that have been proposed to interpret these signals in relation to the thermodynamics and kinetics of interfacial and intramolecular electron transfer and active site chemistry. We list the corresponding equations in forms that are ready to use for fitting, and the commands that run these fits in the open source software QSoas. We relate these models to those that have been used for characterizing small synthetic redox catalysts diffusing in solution.
\end{abstract}

Keywords: Electrocatalysis, Molecular catalysts, Protein film voltammetry, Enzymes

\section{Highlights}

- Models explain the voltammetric response of catalysts attached to rotating electrodes

- The steady-state responses report on the properties of the catalytic intermediates 
- Redox-driven and slow conversion between active/inactive states results in hysteresis

- The open source software QSoas makes it easy to adjust the model to the data

- The models developed for enzymes could be used in studies of molecular catalysts

\section{Introduction}

Living organisms use enzymes for the catalysis of many important reactions. Electrochemists have actively engaged in developing methods for using these enzymes; in contrast we focus here on how electrochemical methods can be helpful for understanding how enzymes work. This fundamental challenge has broad implications in the context of electrocatalysis, considering that certain redox enzymes catalyse reactions that are very important for the activation of small molecules and the production of solar fuels.

The business end of these redox enzymes, which are incredibly large and complex proteins, is a small active site that most often consists of an organic or inorganic cofactor. This active site is deeply buried in the protein matrix and connected to the exterior by amino acid and water molecules that transfer protons, cavities that guide the diffusion of the substrate and product, and chains of cofactors that mediate electron transfer (ET). The chain of redox relays that mediate ET between the active site and the protein surface can also be used for achieving direct ET to or from an electrode: having the surface exposed redox relay close to the electrode surface wires up the active site [1, 2].

This paper is the first comprehensive review of the models that have been developed to quantitatively interpret the voltammetry of redox enzymes since 2008 [3]. Progress has since been made in several directions including the interpretation of voltammograms that show catalytic currents in both directions and/or strong hysteresis, and how the voltammetric features depend on the kinetics and thermodynamics of intramolecular ET along the redox chain that connects the active site to the electrode. Here we summarize all available models and underlying assumptions, and explain how they can easily be implemented in a particular open source software [4, •]. Following up on recent papers about the differences between enzymes and molecular or solid-state electrocatalysts [5, 6], we explain here how the models originally developed 
for enzymes compare with those that are used to explain the voltammetry of molecular catalysts, and we argue that the knowledge acquired by studying the former should benefit the characterization of the latter.

\section{General considerations}

The current observed with adsorbed enzyme molecules is proportional to the average turnover frequency of the adsorbed enzymes, and to the value of the electroactive coverage $\Gamma$. In most cases $\Gamma$ is unknown, which prevents the absolute value of the turnover frequency to be determined, but important information can be obtained from the relative change in current that results from a change in experimental conditions: addition of substrate or inhibitor [7-13], illumination [14-17], or change in electrode potential (E) as illustrated below.

The voltammetry of enzymes has been analyzed in terms of a "resistance model," where the current is expressed as a sum of reciprocal current contributions for interfacial ET, enzyme kinetics and mass transport towards the rotating disc electrode ( $\mathrm{RDE}): 1 / i=1 / i_{E}+1 / i_{\text {cat }}+1 / i_{\text {Levitch }}$. The merit of this model is that it lists the processes that may limit the catalytic current. However, it cannot be used to quantitatively analyze the response since the three terms are actually not independent. It is more useful to obtain a current equation from a realistic kinetic scheme, as proposed early on in refs [18, 19].

Taking into account mass-transport towards the RDE results in current equations of considerable complexity [3, 19, 20]. Instead, we shall assume here that fast electrode rotation rate prevents substrate depletion, a situation that is favorable for mechanistic studies.

\section{Steady-state, two-electron, one-way catalysis, sigmoidal shapes}

We first discuss the case of an enzyme that irreversibly catalyses a twoelectron reaction, ignoring the ET chain. We call this the $\mathrm{EEC}_{\mathrm{i}}$ model, where $\mathrm{E}$ is a redox transformation of the active site and $\mathrm{C}_{\mathrm{i}}$ the irreversible transformation of substrate into product. We denote "O", "I" and "R" as the oxidized, intermediate (half-reduced) and reduced forms of the active site, respectively.

Changing the electrode potential changes the redox state of the active site and the resulting catalytic current, which is proportional to the steadystate fraction of active site that is in the right oxidation state for turning 


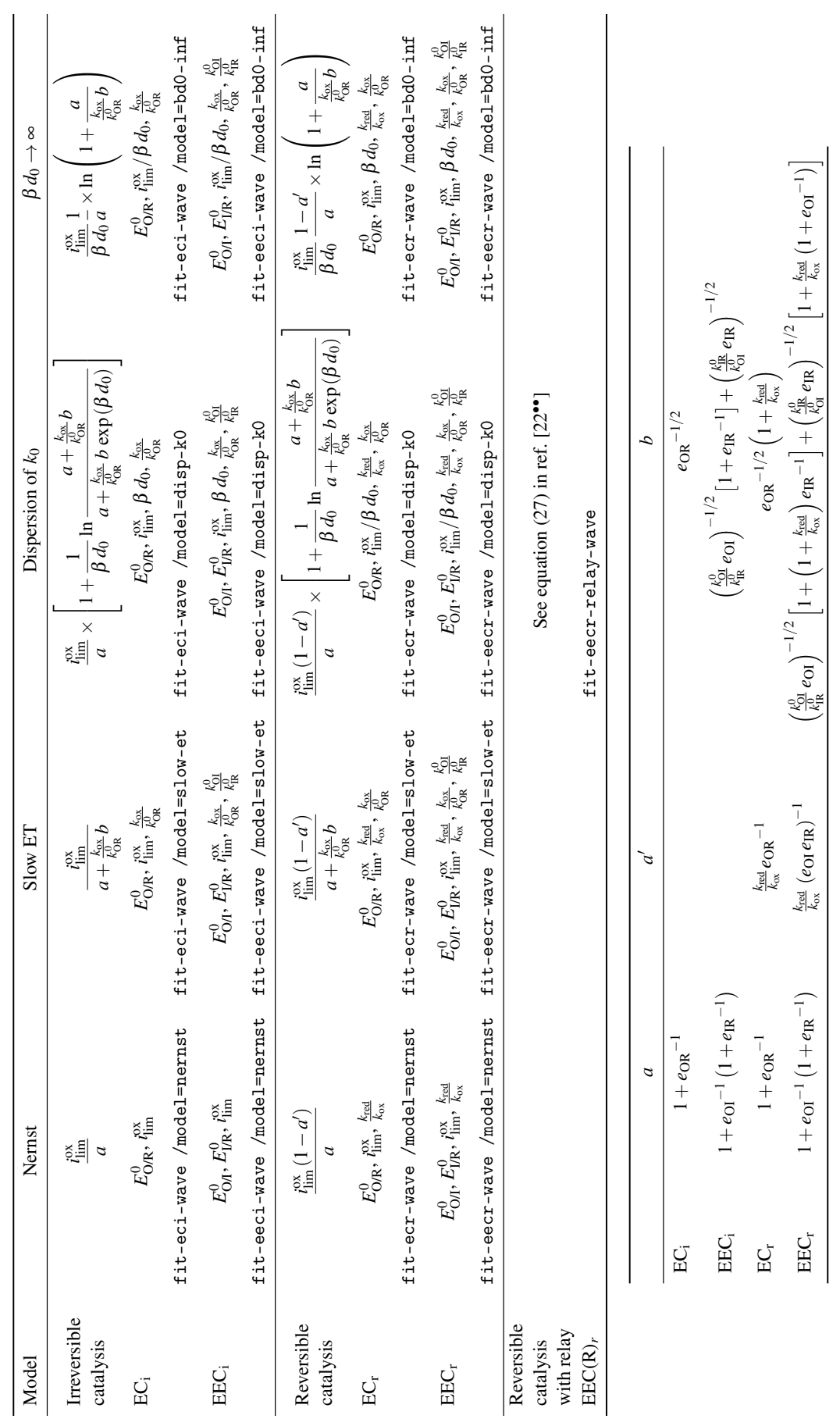

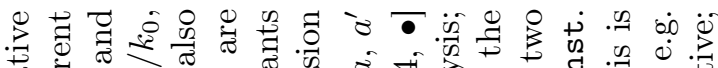

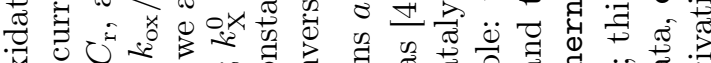

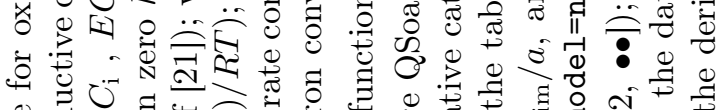

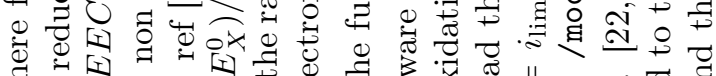

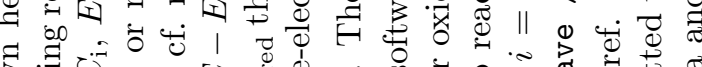

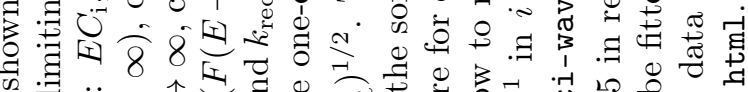
क

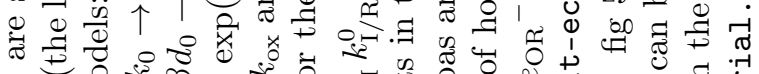

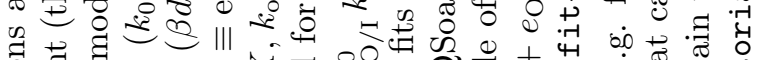

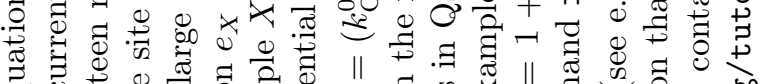

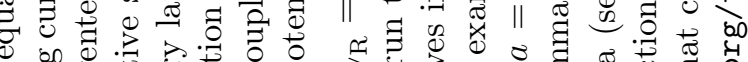

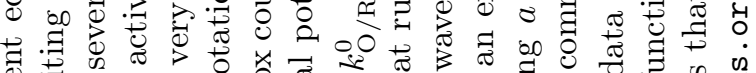

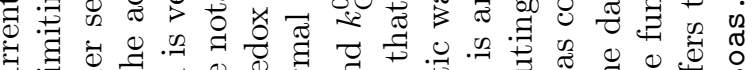

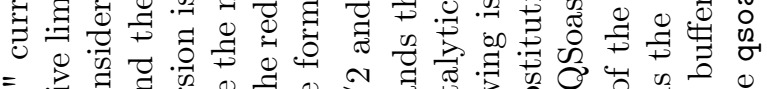
$=$.

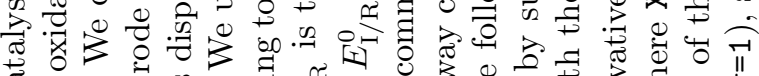

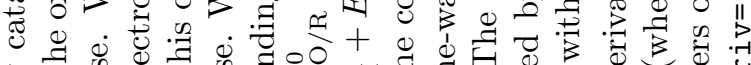

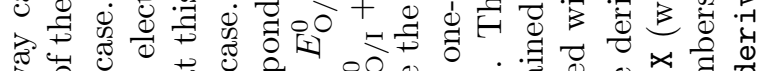

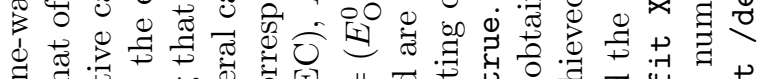

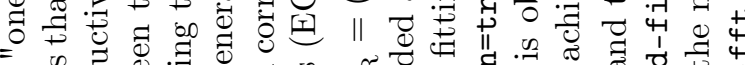

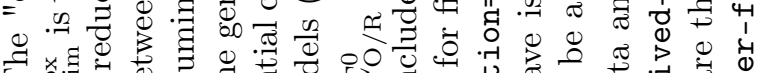

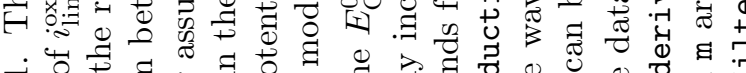
-

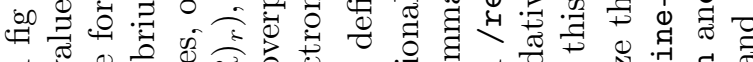
:

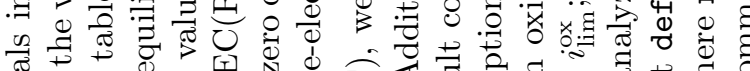

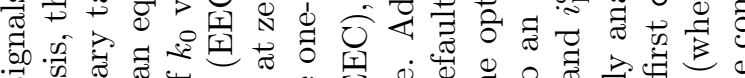

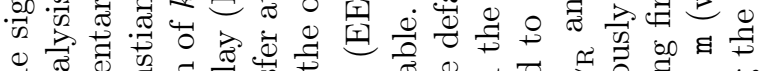

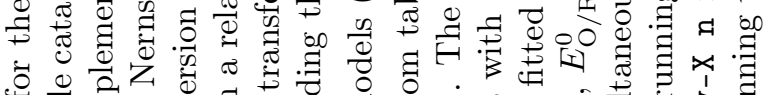

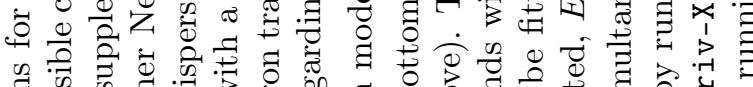

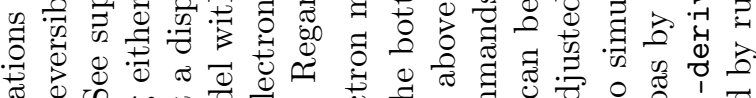

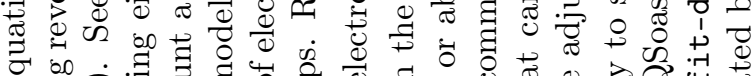

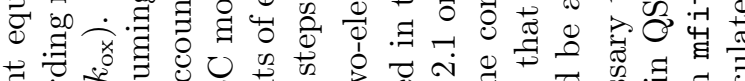

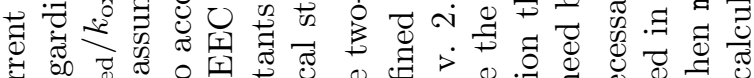

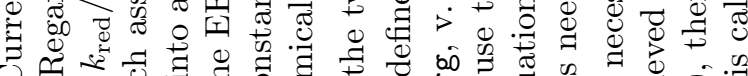

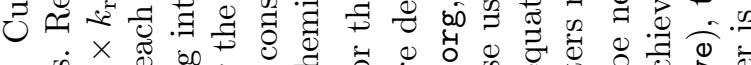

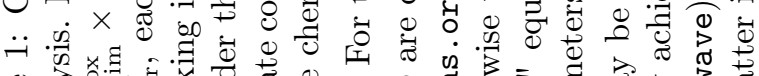

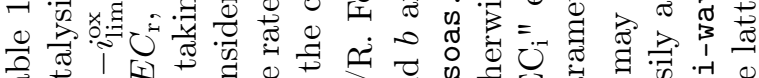

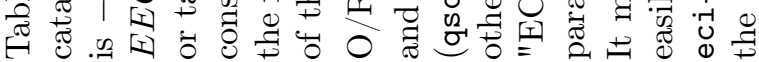


over the substrate. The position of the waveshape along the $E$ axis therefore informs on the two formal reduction potentials of the active site. However, just like Michaelis constants are not necessarily true dissociation constants (see box 1), it is now clear that these potentials are not necessarily true thermodynamic parameters.

In the model, there is no need to assume a priori that substrate binds to a particular redox state of the active site. This information about substrate binding can be obtained a posteriori by examining the dependence of the formal reduction potential of the active site on substrate concentration [23, 24]. Substrate binding is one of the reasons why the catalytic potential may deviate from the reduction potential of the active site measured under nonturnover conditions (note that such deviation occurs anyway according to all models that are more complex than EEC, see Box 1).

The current goes from zero at low driving force to a plateau value $\left(i_{\lim }^{\mathrm{ox}}\right)$ that only depends on the pseudo-first-order rate $k_{\text {ox }}$ of the $\mathrm{C}_{\mathrm{i}}$ step $\left(k_{\mathrm{ox}}\right.$ depends on substrate concentration). The steepness of the sigmoidal wave is characterized by an apparent number of electrons $n$, determined either by fitting a sigmoidal function $\left(i=i_{\lim }^{\text {ox }} /\left(1+\exp n F / R T\left(E_{\text {cat }}-E\right)\right)\right)$ or from the slope of a plot of $\log \left(i / i_{\text {lim }}^{\text {ox }}-1\right.$ ) against $E$ (as shown herein in the insets in fig 1 , and in ref [23]).

Considering e.g. oxidative catalysis, if the intermediate form of the active site is stable over a large range of potential $\left(E_{\mathrm{O} / \mathrm{I}}>E_{\mathrm{I} / \mathrm{R}}\right)$, the signal is a one-electron wave centered on the potential of the $\mathrm{O} / \mathrm{I}$ couple of the active site (fig 1e). If $E_{\mathrm{O} / \mathrm{I}}$ is close to $E_{\mathrm{I} / \mathrm{R}}$, the steepness of the wave changes from $n=2$ at the onset of catalysis to $n=1$ near the plateau [23] (fig 1e). If the intermediate redox state is unstable $\left(E_{\mathrm{O} / \mathrm{I}}<E_{\mathrm{I} / \mathrm{R}}\right)$, the signal is a twoelectron wave centered on the 2-electron reduction potential $E_{O / R}$. Note that the $\mathrm{EC}_{i}$ model is a limiting case of the $\mathrm{EEC}_{i}$ model: when $E_{\mathrm{O} / \mathrm{I}}>E_{\mathrm{I} / \mathrm{R}}$ the position of the oxidative wave depends only on $E_{\mathrm{O} / \mathrm{I}}$.

Interfacial ET limitations can be taken into account by using the simple Butler-Volmer equation with $\alpha=1 / 2$. (We denote $k_{0}$ as the interfacial ET rate constant at zero driving force.) Additional terms in the rate equation contribute in proportion to the ratio of $k_{\mathrm{ox}} / k_{0}$ and broaden the wave all the more that the current is large (that is, near the plateau), leaving the plateau value unchanged (fig 1f).

The above model is made more general by considering that a distribution of enzyme molecule orientations on the electrode results in a distribution of $k_{0}$ values (fig 51 in ref $[3$ ] and refs [20, 21, 25][26, •]). The model assumes 
that (i) the rate of interfacial ET is $k_{0} \exp (-\beta d)$, where $d$ is the distance over which interfacial ET occurs (the distance between the electrode and the surface exposed redox center) and $\beta$ is a decay coefficient, and (ii) $d$ is uniformly distributed between $d_{\min }$ and $d_{\min }+d_{0}$, hence $d_{0}$ is the width of the distance distribution. If $d_{0}$ is large, the current ends on an inclined (instead of truly horizontal) plateau, the slope of which is proportional to the limiting current that is not reached in the experimental potential window (eq 10 in ref [21] and fig $1 \mathrm{~h})$.

In many enzymes, ET between the electrode and the active site is mediated by a linear chain of one-electron redox relays. Following the observation that the wave of sulfite oxidase deviates from the potential of the active site molybdenum [27], a model was proposed to explain that the wave potential may vary between the potential of the relay and that of the active site, depending on the competition between intramolecular electron transfer and active site chemistry (see the discussion of fig 18 in ref [3] and ref [28]). The corresponding maths is necessarily heavy because the effect of intramolecular ET on the voltammogram of an enzyme that has a two-electron active site and $N$ one-electron relays requires that the kinetic model include the transitions between $3 \times 2^{N}$ microstates. General conclusions can be drawn from the

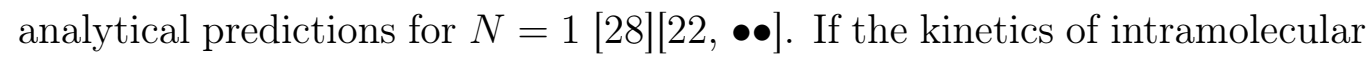
ET is fast, the redox chain is "transparent": the catalytic wave only depends on the properties of the active site and on the kinetics of interfacial ET. If intramolecular ET limits the turnover rate, then the position and magnitude of the wave depend on the potentials of both the active site and the relay, and on the kinetics of both intramolecular ET and active site chemistry.

\section{Steady-state, one- and two-electron, bidirectional catalysis, sig- moidal shapes}

When the enzyme is a "good" catalyst in the two directions of the redox reaction and if both the substrate and the product are present in solution, the voltammetric current goes from negative to positive as the electrode potential is varied, crossing $i=0$ at the equilibrium potential (or "open circuit potential", OCP) (figs $1 \mathrm{i}-\mathrm{p}$ ). The OCP equates the Nernst potential of the substrate/product couple [23, 29 31]. This thermodynamic parameter does not characterize the enzyme, although its determination using protein film voltammetry may be nevertheless very valuable [32, •][33, •]. 
Kinetic models for bidirectional electrocatalysts have been proposed only

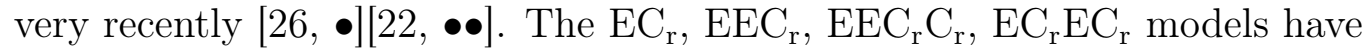
all been considered (where $\mathrm{C}_{\mathrm{r}}$ is a reversible chemical reaction, one of which is the transformation between substrate and product). Even in the absence of interfacial ET limitations, various shapes can be predicted depending on the parameters, from a one- (fig 1i) or two-electron sigmoid that is offset along the $\mathrm{Y}$ axis (fig 1i), to a sum of two one-electron sigmoids shifted along the $E$ axis on either side of the OCP (fig $1 \mathrm{~m}$ ).

Of particular interest is the discussion of the factors that determine these "catalytic overpotentials" in the two directions of the reaction. (The overpotential is defined here as the difference between the position of the catalytic signal and the OCP [22, 34, 35].) Thermodynamic stability of the half reduced form of the active site $\left(E_{\mathrm{O} / \mathrm{I}}>E_{\mathrm{I} / \mathrm{R}}\right)$ is one of several possible reasons for the existence of a catalytic overpotential (fig $1 \mathrm{~m}$ ). Box 1 comments on the interpretation of the parameters obtained from the fit.

Note that the $\mathrm{EC}_{r}$ model would be a limiting case of the $\mathrm{EEC}_{r}$ model only if $E_{\mathrm{O} / \mathrm{I}}-E_{\mathrm{I} / \mathrm{R}}=R T / F \log (4)$, which is not expected to be true over a wide range of experimental conditions [22, $\bullet \bullet]$.

Slow interfacial ET and a distribution of $k_{0}$ values broadens the bidirectional catalytic wave in a manner that is similar to that discussed above for

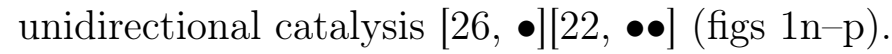

A kinetic model for bidirectional 2-electron catalysis that explicitely takes into account intramolecular ET through a single one-electron relay has been discussed in ref $[22, \bullet \bullet]$. The kinetics of intramolecular ET affects the voltammetric features (the two catalytic potentials) in a non trivial manner. An alternative approach postulates that intramolecular ET is so slow that one can consider only the relay and not the active site [26, •[36]; in that case of course, the predicted signal is a one-electron wave (fig 1i) centered on the potential of the relay. According to this model, a separation between the cathodic and anodic waves (catalytic overpotential) can only be the consequence of slow interfacial ET, which broadens the signal and shifts each reaction towards greater driving force (fig $1 \mathrm{j}$; the value of $k_{2} / k_{0}$ is very large for the signal in this plot, in order to accentuate the effect). This is unlike the models that take into account the three redox states of the active site (see above and fig $1 \mathrm{~m}$ ). 


\section{Seady-state, two-electron, complex waveshapes}

The steady-state response sometimes exhibits a sigmoidal current boost or decrease that is superimposed onto the "main" catalytic response [37, as recently illustrated in studies of flavo- [38], molybdo- [39] or heme-enzymes [40 42. This may result from allosteric effects: active site chemistry and/or intramolecular ET kinetics may be affected by the redox state of a center that is remote from the active site. However, kinetic models that merely take into account slow substrate binding to different redox states of the active site also give current equations that are useful in this context [3, 43, 44]. These models depend on many parameters that may be difficult to determine independently, and data analysis most often consists in fitting ad hoc combinations of sigmoidal functions [45], and interpreting their dependence on experimental parameters, including substrate concentration and/or $\mathrm{pH}$.

\section{Departure from steady-state}

The voltammetric response of many metalloenzymes is altered by a redoxdriven transformation between active and inactive states that is slow on the time scale of turnover and slow on the time scale of the voltammetry.

$$
\text { Active } \underset{k_{a}(E)}{\rightleftharpoons} \text { Inactive }
$$

(In)activation clearly shows up in the voltammetry as a hysteresis that cannot be explained by film loss (fig 2), as initialy exemplified by NiFe hydrogenases [49, 50, and more recently by FeFe hydrogenases [47, 51, 52, [53, •] and molybdo-enzymes [46, 54].

In initial studies of the mechanism of (in)activation, the dependence of the rate constants $k_{i}$ and $k_{a}$ on potential must be determined in chronoamperometry experiments. Indeed, after a potential step, the catalytic current relaxes towards a new steady-state with a time constant $\tau=1 / k_{i}+1 / k_{a}$. Both the magnitude and time constant of the transient signal must be interpreted to independently determine $k_{i}$ and $k_{a}$ at a given potential, and the experiment must repeated at different potentials to determine $k_{i}(E)$ and $k_{a}(E)[55$. This strategy is also useful when two inactive species are formed and the (in)activation kinetics is not first-order [51, 54]. 
Once the dependence of $k_{i}$ and $k_{a}$ on $E$ is known, the time-dependent fraction of active enzyme $(A(t))$ in a voltammetric experiment is obtained by solving $d A(t) / d t=-k_{i} A(t)+k_{a}(1-A(t))$ and the voltammogram at a given scan rate can be calculated by multiplying the steady-state response of the fully active enzyme by the time-dependent $A(t)$ (fig 2) [25, 46, 48, 51, 55].

An equation has also been obtained by combining the $\mathrm{EC}_{r}$ steady-state response with a time-independent function that gives the fraction of enzyme in a particular state (eq 20 in ref [45]). However, this approach cannot account for the hysteresis observed at a given scan rate or for the dependence of the signal on scan rate (fig 2).

The voltammetry resulting from the high-potential reversible inactivation of NiFe hydrogenases has been particularly studied. The rate constant of inactivation $\left(k_{i}\right)$ is slow and independent of $E$ whereas the rate constant of activation $\left(k_{a}\right)$ increases exponentially as the electrode potential decreases [49]. Simple analytical expressions can be deduced and fitted to portions of the voltammograms [48] (fig 2C). The meaning of the so-called "switch potential" ( $E_{\mathrm{sw}}$, the potential where reactivation occurs on the scan towards low potential, fig $2 \mathrm{C}$ ) is now clear: reactivation occurs when $k_{a}(E)$ reaches the same order of magnitude as the time scale of the experiment, which depends on the scan rate $\nu$ (see the discussion of eq. 8 in ref [48]):

$$
k_{a}\left(E_{\mathrm{sw}}\right)=F \nu / R T
$$

Equation 2 explains why in the case of NiFe hydrogenases, the value of $E_{\mathrm{sw}}$ changes in proportion to $\log (\nu)$ [48], and it can also be used when two inactive species successively reactivate on the downward potential sweep [52, 56].

\section{The case of small synthetic catalysts}

Molecular catalysts are nearly always studied in the situation where the catalysts are allowed to diffuse to and from the stationary electrode [57]. If "secondary phenomena" such as substrate depletion and interfacial ET limitations are negligible, the voltammetric signal is a one-electron sigmoid. The popular "foot of the wave analysis" [58] consists of deducing the plateau current (hence the turnover frequency of the catalyst) from the exponential increase in current at the onset of the signal and the mid-point potential of the one-electron sigmoid, which is assumed to equate the potential of the redox couple that triggers catalysis, determined in the absence of substrate. 
This hypothesis, however, is only valid in the framework of an EC model, provided that the chemical step does not shift the equilibrium between the redox catalyst and the electrode. In more realistic models $\left(\mathrm{EEC}_{\mathrm{i}} \mathrm{C}_{\mathrm{i}}, \mathrm{EC}_{\mathrm{i}} \mathrm{EC}_{\mathrm{i}}\right)$, the use of this method encounters further challenges; the wave may not be centered on the redox potential of the catalyst measured under non turnover conditions [59, $\bullet \bullet$ ] and there is therefore no information in the foot of the wave. In this case, the turnover frequency of the catalyst must be determined

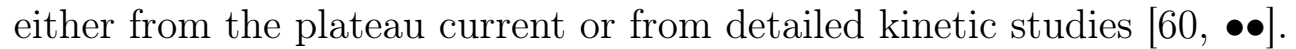

Very complex and informative current responses have been observed with adsorbed enzymes, and it is surprising that the response of molecular catalysts could be characterized by just a mid wave potential and a plateau current. Catalyst diffusion probably blurs meaningful features of the current response (in addition to making realistic kinetic models difficult to solve), and we expect that re-examining this voltammetry after the catalysts are attached to flat RDEs should produce different results. Recently, various methods have been proposed to attach molecular catalysts onto electrodes [61 65] [66, $\bullet[67, \bullet \bullet]$, often with the aim of enhancing stability and usability. The voltammetry of Ni-diphosphine hydrogenase mimicks attached to a planar rotating graphite electrode demonstrates complex and information rich

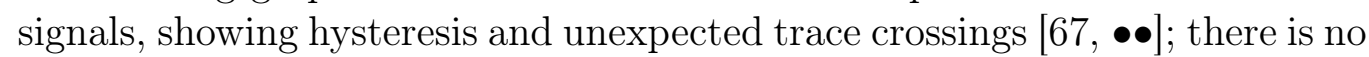
doubt that a wealth of mechanistic information could be obtained from its detailed examination. In contrast, the response of similar complexes attached to nanostructured materials is featureless [62], probably because substrate and/or electron transport within the electrode material is a limiting factor.

The question of whether or not the presence of the electrode may affect the properties of the electrocatalyst is even more acute in the case of small molecules than in the case of enzymes (whose active site is buried in the protein matrix and insulated from the electrode). With enzymes, it has often been possible to design experiments in homogeneous solution that support the conclusions from electrochemical experiments to confirm that a particular feature observed for the adsorpbed enzyme is not the result of the interaction between the protein and the electrode [68]. Comparing the properties of the adsorbed catalysts to those of freely diffusing molecular catalysts [65] will also be an important step in the electrochemical study of molecular catalysts. 


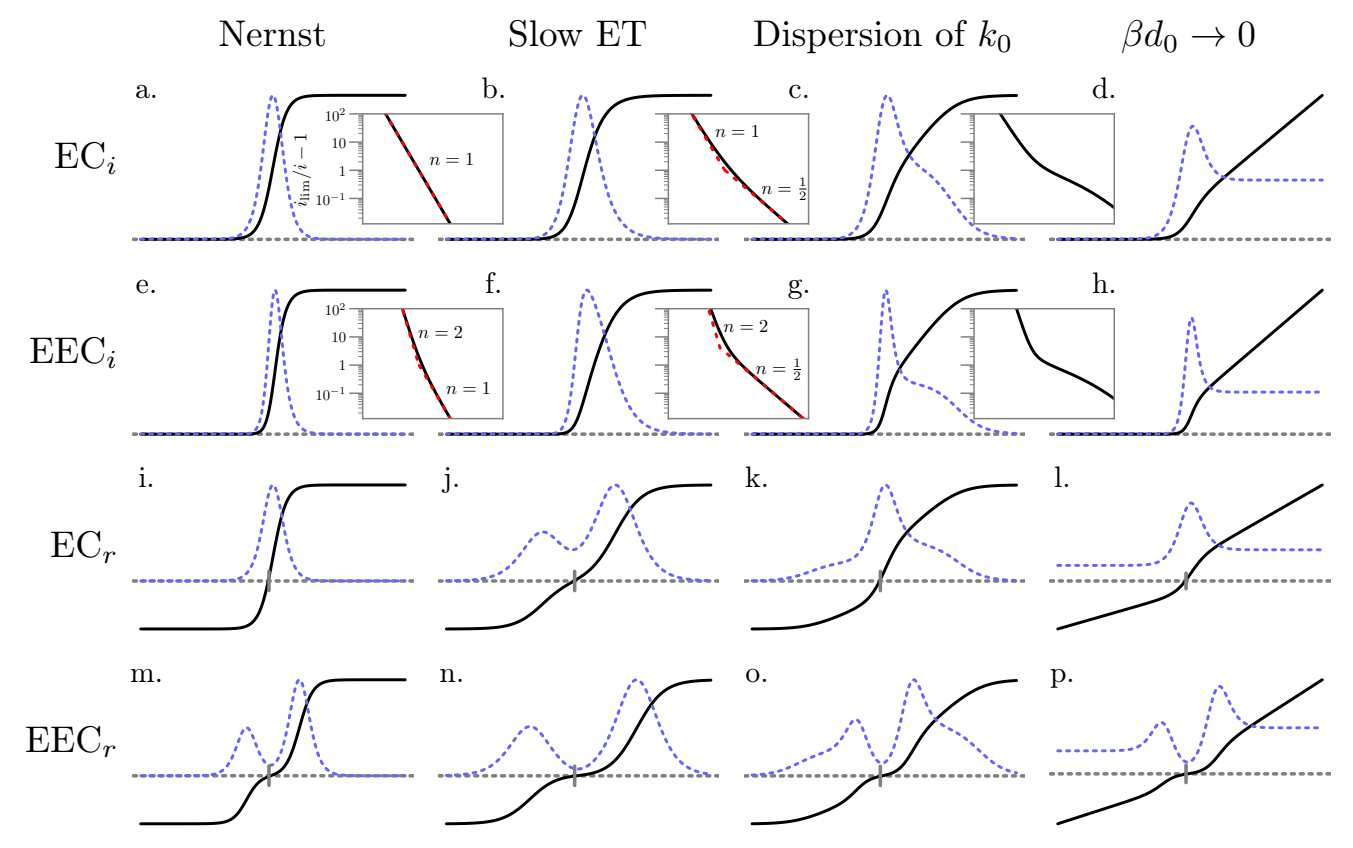

Figure 1: Steady-state catalytic waveshapes for adsorbed catalysts and enzymes. The black lines show the various catalytic wave shapes $(i$ against $E$ ) for adsorbed catalysts, predicted by the $\mathrm{EC}_{\mathrm{i}}, \mathrm{EEC}_{\mathrm{i}}$ (substrate oxidation only), $\mathrm{EC}_{\mathrm{r}}$, and $\mathrm{EEC}_{\mathrm{r}}$ models (rows 1 to 4, respectively), considering either Nernstian equilibrium between the catalyst and the electrode (1st column), or the effect of slow interfacial ET (second column), and a dispersion of $k_{0}$ values (3rd and 4 th columns, $k_{0}$ and $\beta d_{0}$ are defined in the main text). The shapes allowed by the two-electron models (EEC) are actually more diverse than these illustrations suggest. The insets show the plots of $\log \left(i_{\text {ilim }} / i-1\right)$ against $E$, with slopes indicated as multiples of $-n F / R T$. Vertical ticks in panels $\mathrm{i}-\mathrm{p}$ indicate the OCP values. The 1st derivatives of the signals $(d i / d E)$ are shown as dashed blue lines. Table 1 lists the corresponding equations. 

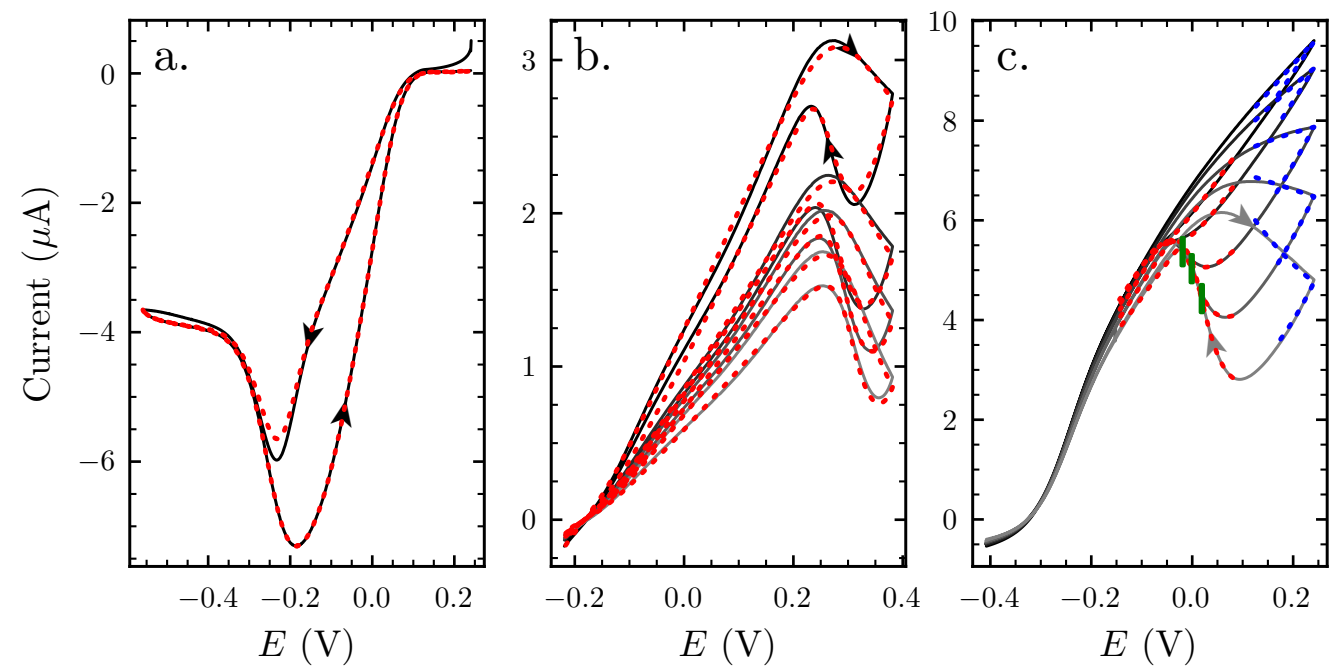

Figure 2: Large hysteresis resulting from the slow, reversible conversion between active and inactive forms of the enzyme (all data recorded at a RDE). The dotted lines are the fits of either a simulated signal (panels a and b), or simple functions that describe portions of the CV (panel c). Panel a: nitrate reduction by $R$. sphaeroides NapAB [46], at $\nu=20 \mathrm{mV} / \mathrm{s}$. Panel b: $\mathrm{H}_{2}$-oxidation and production by $C$. reinhardtii $\mathrm{FeFe}$ hydrogenase, at $\nu$ in the range $2-20 \mathrm{mV} / \mathrm{s}$ [47. Panel c: $\mathrm{H}_{2}$ oxidation by the V74N mutant of $D$. fructosovorans NiFe hydrogenase, at $\nu$ in the range $0.5-10 \mathrm{mV} / \mathrm{s}$, and the fits of eq 5 and 7 in ref [48, (red and blue dotted lines, obtained with the QSoas commands mfit-slow-scan-lp and mfit-slow-scan-hp, respectively). In panel c, vertical ticks mark the values of $E_{\mathrm{sw}}$ at each scan rate. 
A general concern in enzyme kinetics is that kinetic models based on different hypotheses may produce the same rate equation. This implies that the parameters in the rate equation have intrinsically ambiguous meaning.

For example, it is well known that all models in the table below give the Michaelis-Menten rate law, but with different meanings for $v_{m}$ and $K_{M}$; this leads to endless debates about whether or not the value of $K_{M}$ can be interpreted as a thermodynamic parameter (a true dissociation constant). Based on the results of steady-state measurements alone, it is not possible to differentiate between these possibilities.

\begin{tabular}{lcc} 
Models giving rate equation $v=v_{m} /\left(1+K_{M} /[S]\right)$ & $v_{m}$ & $K_{M}$ \\
\hline$E+S \stackrel{K_{d}}{\rightleftharpoons} E S \rightarrow E+P$ & $k_{2} C_{E}$ & $K_{d}$ \\
$E+S \stackrel{k_{1} / k_{-1}}{\rightleftharpoons} E S \stackrel{k_{2}}{\rightarrow} E+P$ & $k_{2} C_{E}$ & $\frac{k_{2}+k_{-1}}{k_{1}}>K_{d}$ \\
$E+S \stackrel{k_{1}}{\rightarrow} E S \stackrel{k_{2}}{\rightarrow} E+P$ & $k_{2} C_{E}$ & $\frac{k_{2}}{k_{1}}$ \\
$E+S \stackrel{k_{1} / k_{-1}}{\rightleftharpoons} E S \stackrel{k_{2}}{\rightarrow} E S^{\prime} \stackrel{k_{3}}{\rightarrow} E+P$ & $\frac{k_{2} k_{3} C_{E}}{k_{2}+k_{3}}$ & $\frac{k_{3}}{k_{2}+k_{3}} \frac{k_{-1}+k_{2}}{k_{1}}$ \\
\hline
\end{tabular}

The same considerations apply in electrochemical studies. In Table 1 we only listed the equations of the EEC models; not those of the related ECEC \& EECC models, because they are identical. However, the meaning of the catalytic potentials is different and is model-dependent. In particular, only in the case of the simplest EEC models are the catalytic potentials determined

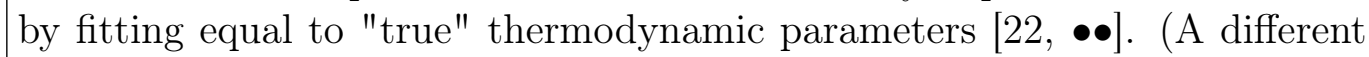
equation is only obtained if one simultaneously considers intra and intermolecular ET, which is the $\operatorname{EEC}_{\mathrm{r}}(\mathrm{R})$ model in ref $[22, \bullet \bullet]$ and in Table 1.) This issue is also relevant in the case of a diffusing catalyst, as evidenced in the equations recently derived for the $\mathrm{EEC}_{i} \mathrm{C}_{i}$ and $\mathrm{EC}_{i} \mathrm{EC}_{i}$ reaction schemes $[59, \bullet \bullet]$ (the corresponding $\mathrm{C}_{r}$ cases have not been considered yet).

Box 1: The parameter ambiguity issue, in solution kinetics and in electrochemical studies of adsorbed or diffusing catalysts. 


\section{Acknowledgements}

The studies in our group could not have been carried out without the collaboration of many biochemists. For working with us, we thank Hervé Bottin, Myriam Brugna, Holger Dobbek, Marie Thérèse Giudici-Orticoni, Axel Magalon, Isabelle Meynial-Salles, Iñes Cardoso Pereira, Monique Sabaty, and, particularly, Sébastien Dementin. We are grateful to Darren Buesen (Bochum University, Germany) for critically reading the manuscript.

\section{Funding Source Declaration}

Our work is supported by CNRS, Aix Marseille Université, Agence Nationale de la Recherche (ANR-12-BS08-0014, ANR-14-CE05-0010, ANR-15CE05-0020) and the A*MIDEX grant (ANR-11-IDEX-0001-02) funded by the French Government "Investissements d'Avenir" program.

\section{Declaration of Interest}

$\mathrm{VF}$ declares financial interest in the sale of the pre-built binaries of the open source program QSoas.

\section{References}

\section{References}

[1] L. J. Jeuken, Structure and modification of electrode materials for protein electrochemistry., Advances in biochemical engineering/biotechnology (2016).

[2] M. Frasconi, F. Mazzei, T. Ferri, Protein immobilization at gold-thiol surfaces and potential for biosensing, Analytical and Bioanalytical Chemistry 398 (2010) 15451564 .

[3] C. Léger, P. Bertrand, Direct electrochemistry of redox enzymes as a tool for mechanistic studies, Chem. Rev. 108 (2008) 2379-2438.

[4] V. Fourmond, QSoas: A versatile software for data analysis, Anal. Chem. 88 (2016) $5050-5052$.

- This paper describes a "swiss knife army" program for the analysis of electrochemical data, including the fitting of the models described herein using the commands listed in Table 1.

[5] J. Masa, W. Schuhmann, Electrocatalysis and bioelectrocatalysis - distinction without a difference, Nano Energy (2016). http://dx.doi.org/10.1016/j.nanoen. 2016.04.007. 
[6] S. Shleev, V. Andoralov, D. Pankratov, M. Falk, O. Aleksejeva, Z. Blum, Oxygen electroreduction versus bioelectroreduction: Direct electron transfer approach, Electroanalysis (2016). http://dx.doi.org/10.1002/elan.201600280.

[7] V. Fourmond, M. Sabaty, P. Arnoux, P. Bertrand, D. Pignol, C. Léger, Reassessing the strategies for trapping catalytic intermediates during nitrate reductase turnover., The journal of physical chemistry. B 114 (2010) 3341-3347.

[8] M. Merrouch, J. Hadj-Saïd, L. Domnik, H. Dobbek, C. Léger, S. Dementin, V. Fourmond, $\mathrm{O}_{2}$ inhibition of Ni-Containing $\mathrm{CO}$ dehydrogenase is partly reversible, Chem. Eur. J. 21 (2015) 18934-18938.

[9] A. Abou Hamdan, B. Burlat, O. Gutiérrez-Sanz, P.-P. Liebgott, C. Baffert, A. L. De Lacey, M. Rousset, B. Guigliarelli, C. Léger, S. Dementin, $\mathrm{O}_{2}$-independent formation of the inactive states of NiFe hydrogenase, Nature Chemical Biology 9 (2012) $15-17$.

[10] V. Fourmond, C. Baffert, K. Sybirna, S. Dementin, A. Abou-Hamdan, I. MeynialSalles, P. Soucaille, H. Bottin, C. Leger, The mechanism of inhibition by $\mathrm{H}_{2}$ of $\mathrm{H}_{2}$-evolution by hydrogenases, Chem. Commun. 49 (2013) 6840-6842.

[11] A. Kubas, C. Orain, D. De Sancho, L. Saujet, M. Sensi, C. Gauquelin, I. MeynialSalles, P. Soucaille, H. Bottin, C. Baffert, V. Fourmond, R. B. Best, J. Blumberger, C. Léger, Mechanism of $\mathrm{O}_{2}$ diffusion and reduction in FeFe hydrogenases, Nature Chemistry (2016). http://dx.doi.org/10.1038/nchem.2592.

[12] V. Radu, S. Frielingsdorf, S. D. Evans, O. Lenz, L. J. Jeuken, Enhanced oxygentolerance of the full heterotrimeric membrane-bound [NiFe]-hydrogenase of Ralstonia eutropha., Journal of the American Chemical Society 136 (2014) 8512-8515.

[13] P. Kwan, C. L. McIntosh, D. P. Jennings, R. C. Hopkins, S. K. Chandrayan, C.-H. H. $\mathrm{Wu}, \mathrm{M}$. W. Adams, A. K. Jones, The [NiFe]-hydrogenase of Pyrococcus furiosus exhibits a new type of oxygen tolerance., Journal of the American Chemical Society 137 (2015) 13556-13565.

[14] A. Parkin, C. Cavazza, J. C. Fontecilla-Camps, F. A. Armstrong, Electrochemical investigations of the interconversions between catalytic and inhibited states of the $[\mathrm{FeFe}]$-hydrogenase from Desulfovibrio desulfuricans., Journal of the American Chemical Society 128 (2006) 16808-16815.

[15] A. Ciaccafava, C. Hamon, P. Infossi, V. Marchi, M.-T. T. Giudici-Orticoni, E. Lojou, Light-induced reactivation of $\mathrm{O}_{2}$-tolerant membrane-bound [Ni-Fe] hydrogenase from the hyperthermophilic bacterium Aquifex aeolicus under turnover conditions., Physical chemistry chemical physics : PCCP 15 (2013) 16463-16467. 
[16] M. Sensi, C. Baffert, C. Greco, G. Caserta, C. Gauquelin, L. Saujet, M. Fontecave, S. Roy, V. Artero, P. Soucaille, I. Meynial-Salles, H. Bottin, L. de Gioia, V. Fourmond, C. Léger, L. Bertini, Reactivity of the excited states of the H-Cluster of FeFe hydrogenases, J. Am. Chem. Soc. 138 (2016) 13612-13618.

[17] P. Rodríguez-Maciá, J. A. Birrell, W. Lubitz, O. Rüdiger, Electrochemical investigations on the inactivation of the [FeFe]-hydrogenase from Desulfovibrio desulfuricans by $\mathrm{O}_{2}$ or light under hydrogen producing conditions, ChemPlusChem (2016). http://dx.doi.org/10.1002/cplu.201600508.

[18] A. I. Yaropolov, A. A. Karyakin, S. D. Varfolomeev, I. V. Berezin, Mechanism of $\mathrm{H}_{2}$-electrooxidation with immobilized hydrogenase, Bioelectrochemistry and Bioenergetics 12 (1984) 267-277.

[19] H. A. Heering, J. Hirst, F. A. Armstrong, Interpreting the catalytic voltammetry of electroactive enzymes adsorbed on electrodes, J. Phys. Chem. B 102 (1998) 68896902 .

[20] T. Reda, J. Hirst, Interpreting the catalytic voltammetry of an adsorbed enzyme by considering substrate mass transfer, enzyme turnover, and interfacial electron transport, J. Phys. Chem. B 110 (2006) 1394-1404.

[21] C. Léger, A. K. Jones, S. P. J. Albracht, F. A. Armstrong, Effect of a dispersion of interfacial electron transfer rates on steady state catalytic electron transport in [NiFe]-hydrogenase and other enzymes, J. Phys. Chem. B 106 (2002) 13058-13063.

[22] V. Fourmond, C. Baffert, K. Sybirna, T. Lautier, A. Abou Hamdan, S. Dementin, P. Soucaille, I. Meynial-Salles, H. Bottin, C. Léger, Steady-State catalytic WaveShapes for 2-electron reversible electrocatalysts and enzymes, J. Am. Chem. Soc. 135 (2013) 3926-3938.

- This paper describes the voltammetry expected for a variety of kinetic schemes, with or without electron relay, as shown in fig 1. It also gives a number of reasons why the catalytic potential may depart from the reduction potential of the active site. Emphasis is on the interpretation of the catalytic potentials and overpotentials.

[23] C. Léger, K. Heffron, H. R. Pershad, E. Maklashina, C. Luna-Chavez, G. Cecchini, B. A. Ackrell, F. A. Armstrong, Enzyme electrokinetics: energetics of succinate oxidation by fumarate reductase and succinate dehydrogenase., Biochemistry 40 (2001) 11234-11245.

[24] C. Léger, A. K. Jones, W. Roseboom, S. P. Albracht, F. A. Armstrong, Enzyme electrokinetics: hydrogen evolution and oxidation by allochromatium vinosum [NiFe]hydrogenase., Biochemistry 41 (2002) 15736-15746.

[25] K. So, R. Hamamoto, R. Takeuchi, Y. Kitazumi, O. Shirai, R. Endo, H. Nishihara, Y. Higuchi, K. Kano, Bioelectrochemical analysis of thermodynamics of the catalytic cycle and kinetics of the oxidative inactivation of oxygen-tolerant [NiFe]-hydrogenase, Journal of Electroanalytical Chemistry 766 (2016) 152-161. 
[26] S. V. Hexter, F. Grey, T. Happe, V. Climent, F. A. Armstrong, Electrocatalytic mechanism of reversible hydrogen cycling by enzymes and distinctions between the major classes of hydrogenases., Proceedings of the National Academy of Sciences of the United States of America 109 (2012) 11516-11521.

- This is the very first paper modeling reversible (i.e. bidirectional) catalysis of an adsorbed enzyme based on a $n=1$ kinetic scheme.

[27] S. J. Elliott, A. E. McElhaney, C. Feng, J. H. Enemark, F. A. Armstrong, A voltammetric study of interdomain electron transfer within sulfite oxidase, J. Am. Chem. Soc. 124 (2002) 11612-11613.

[28] C. Léger, F. Lederer, B. Guigliarelli, P. Bertrand, Electron flow in multicenter enzymes: theory, applications, and consequences on the natural design of redox chains., Journal of the American Chemical Society 128 (2006) 180-187.

[29] P. Bianco, J. Haladjian, Electrocatalytic hydrogen evolution at the pyrolytic graphite electrode in the presence of hydrogenase, Journal of The Electrochemical Society 139 (1992) 2428-2432.

[30] J. Hirst, A. Sucheta, B. A. C. Ackrell, F. A. Armstrong, Electrocatalytic voltammetry of succinate dehydrogenase: Direct quantification of the catalytic properties of a complex electron-transport enzyme, J. Am. Chem. Soc. 118 (1996) 5031-5038.

[31] H. R. Pershad, J. L. Duff, H. A. Heering, E. C. Duin, S. P. Albracht, F. A. Armstrong, Catalytic electron transport in chromatium vinosum [NiFe]-hydrogenase: application of voltammetry in detecting redox-active centers and establishing that hydrogen oxidation is very fast even at potentials close to the reversible $\mathrm{H}^{+} / \mathrm{H}_{2}$ value., Biochemistry 38 (1999) 8992-8999.

[32] A. Bassegoda, C. Madden, D. W. Wakerley, E. Reisner, J. Hirst, Reversible interconversion of $\mathrm{CO}_{2}$ and formate by a molybdenum-containing formate dehydrogenase., Journal of the American Chemical Society 136 (2014) 15473-15476.

- This paper reports $\mathrm{CVs}$ obtained with an enzyme that converts $\mathrm{CO}_{2}$ and formate. The waveshapes are those predicted by the $\mathrm{EEC}_{r}$ model.

[33] J. M. Kurth, C. Dahl, J. N. Butt, Catalytic protein film electrochemistry provides a direct measure of the Tetrathionate/Thiosulfate reduction potential., Journal of the American Chemical Society 137 (2015) 13232-13235.

- This paper reports CVs obtained with an enzyme that converts Tetrathionate and Thiosulfate. The waveshapes are those predicted by the $\mathrm{EEC}_{r}$ model.

[34] A. J. Bard, G. Inzelt, F. Scholz, Electrochemical dictionary, Springer, 2012. URL: http://www.worldcat.org/isbn/9783642295515.

[35] A. M. Appel, M. L. Helm, Determining the overpotential for a molecular electrocatalyst, ACS Catal. 4 (2014) 630-633. 
[36] I. Mazurenko, K. Monsalve, J. Rouhana, P. Parent, C. Laffon, A. L. L. Goff, S. Szunerits, R. Boukherroub, M.-T. T. Giudici-Orticoni, N. Mano, E. Lojou, How the intricate interactions between carbon nanotubes and two bilirubin oxidases control direct and mediated $\mathrm{O}_{2}$ reduction., ACS applied materials \& interfaces (2016).

[37] S. J. Elliott, C. Léger, H. R. Pershad, J. Hirst, K. Heffron, N. Ginet, F. Blasco, R. A. Rothery, J. H. Weiner, F. A. Armstrong, Detection and interpretation of redox potential optima in the catalytic activity of enzymes., Biochimica et biophysica acta 1555 (2002) 54-59.

[38] J. M. Hudson, K. Heffron, V. Kotlyar, Y. Sher, E. Maklashina, G. Cecchini, F. A. Armstrong, Electron transfer and catalytic control by the iron-sulfur clusters in a respiratory enzyme, e. coli fumarate reductase., Journal of the American Chemical Society 127 (2005) 6977-6989.

[39] J. Marangon, P. M. Paes de Sousa, I. Moura, C. D. Brondino, J. J. Moura, P. J. González, Substrate-dependent modulation of the enzymatic catalytic activity: reduction of nitrate, chlorate and perchlorate by respiratory nitrate reductase from Marinobacter hydrocarbonoclasticus 617., Biochimica et biophysica acta 1817 (2012) 1072-1082.

[40] C. W. J. Lockwood, B. Burlat, M. R. Cheesman, M. Kern, J. Simon, T. A. Clarke, D. J. Richardson, J. N. Butt, Resolution of key roles for the distal pocket histidine in cytochrome c nitrite reductases, J. Am. Chem. Soc. 137 (2015) 3059-3068.

[41] E. T. Judd, N. Stein, A. A. Pacheco, S. J. Elliott, Hydrogen bonding networks tune proton-coupled redox steps during the enzymatic six-electron conversion of nitrite to ammonia., Biochemistry 53 (2014) 5638-5646.

[42] S. J. Elliott, K. R. Hoke, K. Heffron, M. Palak, R. A. Rothery, J. H. Weiner, F. A. Armstrong, Voltammetric studies of the catalytic mechanism of the respiratory nitrate reductase from Escherichia coli: how nitrate reduction and inhibition depend on the oxidation state of the active site., Biochemistry 43 (2004) 799-807.

[43] B. Frangioni, P. Arnoux, M. Sabaty, D. Pignol, P. Bertrand, B. Guigliarelli, C. Léger, In rhodobacter sphaeroides respiratory nitrate reductase, the kinetics of substrate binding favors intramolecular electron transfer, J. Am. Chem. Soc. 126 (2004) 13281329 .

[44] P. Bertrand, B. Frangioni, S. Dementin, M. Sabaty, P. Arnoux, B. Guigliarelli, D. Pignol, C. Léger, Effects of slow substrate binding and release in redox enzymes, J. Phys. Chem. B 111 (2007) 10300-10311.

[45] S. V. Hexter, T. F. Esterle, F. A. Armstrong, A unified model for surface electrocatalysis based on observations with enzymes, Phys. Chem. Chem. Phys. 16 (2014) $11822-11833$. 
[46] J. G. J. Jacques, B. Burlat, P. Arnoux, M. Sabaty, B. Guigliarelli, C. Léger, D. Pignol, V. Fourmond, Kinetics of substrate inhibition of periplasmic nitrate reductase, Biochimica et Biophysica Acta (BBA) - Bioenergetics 1837 (2014) 1801-1809.

[47] C. Orain, L. Saujet, C. Gauquelin, P. Soucaille, I. Meynial-Salles, C. Baffert, V. Fourmond, H. Bottin, C. Léger, Electrochemical measurements of the kinetics of inhibition of two $\mathrm{FeFe}$ hydrogenases by $\mathrm{O}_{2}$ demonstrate that the reaction is partly reversible, J. Am. Chem. Soc. 137 (2015) 12580-12587.

[48] A. A. Hamdan, P.-P. Liebgott, V. Fourmond, O. Gutiérrez-Sanz, A. L. De Lacey, P. Infossi, M. Rousset, S. Dementin, C. Léger, Relation between anaerobic inactivation and oxygen tolerance in a large series of NiFe hydrogenase mutants, Proceedings of the National Academy of Sciences 109 (2012) 19916-19921.

[49] A. K. Jones, S. E. Lamle, H. R. Pershad, K. A. Vincent, S. P. Albracht, F. A. Armstrong, Enzyme electrokinetics: electrochemical studies of the anaerobic interconversions between active and inactive states of allochromatium vinosum [NiFe]hydrogenase., Journal of the American Chemical Society 125 (2003) 8505-8514.

[50] B. Limoges, J.-M. Savéant, Catalysis by immobilized redox enzymes. diagnosis of inactivation and reactivation effects through odd cyclic voltammetric responses, Journal of Electroanalytical Chemistry 562 (2004) 43-52.

[51] V. Fourmond, C. Greco, K. Sybirna, C. Baffert, P.-H. Wang, P. Ezanno, M. Montefiori, M. Bruschi, I. Meynial-Salles, P. Soucaille, J. Blumberger, H. Bottin, L. De Gioia, C. Léger, The oxidative inactivation of FeFe hydrogenase reveals the flexibility of the H-cluster, Nature Chemistry 6 (2014) 336-342.

[52] P. Ceccaldi, K. Schuchmann, V. Muller, S. Elliott, The hydrogen dependent $\mathrm{CO}_{2}$ reductase: the first completely CO-tolerant FeFe-hydrogenase, Energy Environ. Sci. (2016). http://dx.doi.org/10.1039/c6ee02494g

[53] V. Hajj, C. Baffert, K. Sybirna, I. Meynial-Salles, P. Soucaille, H. Bottin, V. Fourmond, C. Léger, FeFe hydrogenase reductive inactivation and implication for catalysis, Energy Environ. Sci. 7 (2014) 715-719.

- This paper reports the analysis of the time evolution of the steady state catalytic CVs obtained with a FeFe hydrogenase after a reductive potential pulse. The film is shown to be heterogeneous, with two species responding as predicted by the $\mathrm{EEC}_{r}$ model, and the time course of the proportions of each species can be determined.

[54] P. Ceccaldi, J. Rendon, C. Léger, R. Toci, B. Guigliarelli, A. Magalon, S. Grimaldi, V. Fourmond, Reductive activation of E. coli respiratory nitrate reductase, Biochimica et Biophysica Acta (BBA) - Bioenergetics 1847 (2015) 1055-1063.

[55] V. Fourmond, P. Infossi, M.-T. Giudici-Orticoni, P. Bertrand, C. Léger, "Two-Step" chronoamperometric method for studying the anaerobic inactivation of an oxygen tolerant NiFe hydrogenase, J. Am. Chem. Soc. 132 (2010) 4848-4857. 
[56] P. Ceccaldi, M. C. Marques, V. Fourmond, I. C. Pereira, C. Léger, Oxidative inactivation of NiFeSe hydrogenase, Chem. Commun. 51 (2015) 14223-14226.

[57] J. M. Savéant, Elements of molecular and biomolecular electrochemistry : an electrochemical approach to electron transfer chemistry, Wiley-Interscience, 2006. URL: http://www.worldcat.org/isbn/9780471758075.

[58] C. Costentin, S. Drouet, M. Robert, J.-M. Savéant, Turnover numbers, turnover frequencies, and overpotential in molecular catalysis of electrochemical reactions. cyclic voltammetry and Preparative-Scale electrolysis, J. Am. Chem. Soc. 134 (2012) 1123511242 .

[59] C. Costentin, J.-M. Savéant, Multielectron, multistep molecular catalysis of electrochemical reactions: Benchmarking of homogeneous catalysts, CHEMELECTROCHEM 1 (2014) 1226-1236.

-• This paper describes the voltammetry expected for catalysts that diffuse in solution and exchange electrons directly with the stationnary electrode. Like in the case

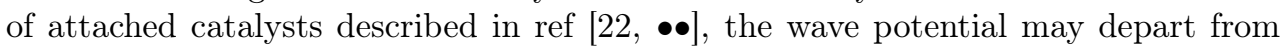
the potential of the catalyst.

[60] V. Artéro, J.-M. Savéant, Toward the rational benchmarking of homogeneous $\mathrm{H}_{2}$ evolving catalysts, Energy Environ. Sci. 7 (2014) 3808-3814.

- This paper explains how the foot of the catalytic wave can be analysed to determine the turnover frequency of the diffusing catalyst, on condition that the wave is centered on the potential of the catalysts determined under non-turnover conditions.

[61] R. M. Kellett, T. G. Spiro, Cobalt porphyrin electrode films as hydrogen catalysts, Inorg. Chem. 24 (1985) 2378-2382.

[62] A. Le Goff, V. Artéro, B. Jousselme, P. D. D. Tran, N. Guillet, R. Métayé, A. Fihri, S. Palacin, M. Fontecave, From hydrogenases to noble metal-free catalytic nanomaterials for $\mathrm{H}_{2}$ production and uptake., Science 326 (2009) 1384-1387.

[63] E. W. McQueen, J. I. Goldsmith, Electrochemical analysis of Single-Walled carbon nanotubes functionalized with Pyrene-Pendant transition metal complexes, J. Am. Chem. Soc. 131 (2009) 17554-17556.

[64] L. Tong, M. Gothelid, L. Sun, Oxygen evolution at functionalized carbon surfaces: a strategy for immobilization of molecular water oxidation catalysts, Chem. Commun. 48 (2012) 10025-10027.

[65] A. K. Das, M. H. Engelhard, R. M. Bullock, J. A. S. Roberts, A Hydrogen-Evolving $\mathrm{Ni}(\mathrm{P} 2 \mathrm{~N} 2) 2$ electrocatalyst covalently attached to a glassy carbon electrode: Preparation, characterization, and catalysis. comparisons with the homogeneous analogue, Inorg. Chem. 53 (2014) 6875-6885. 
[66] H. Tian, Molecular catalyst immobilized photocathodes for Water/Proton and carbon dioxide reduction, ChemSusChem 8 (2015) 3746-3759.

- This paper describes various methods used for attaching molecular catalysts to electrodes.

[67] P. Rodriguez-Maciá, A. Dutta, W. Lubitz, W. J. Shaw, O. Rüdiger, Direct comparison of the performance of a bio-inspired synthetic nickel catalyst and a [NiFe]hydrogenase, both covalently attached to electrodes, Angew. Chem. Int. Ed. 54 (2015) 12303-12307.

-• This paper shows the complex voltammetric response of a synthetic $\mathrm{H}_{2}$ oxidation/production catalyst immobilized onto a flat rotating disc electrode.

[68] V. Fourmond, C. Léger, Protein electrochemistry: questions \& answers, Adv Biochem Eng Biotechnol (2016).dx.doi.org/10.1007/10_2015_5016. 